affected by a chemical substance. It is as though, as Schade suggests, the glycolytic ferment were a sort of catalyzer which might be thought of as affected by the thyroid secretion as catalase may be affected by cranids. 'This seems to me much simpler than the hypothesis that the activity of the pancreas itself is in some way inhibited by the activity of the thrroid.

We know so little about the action of the hypophysis that it is difficult to discuss it here; but it may be recalled that glycosuria sometimes occurs in disease of the hypophysis, and Borchardt has been able to produce it by injections of hypophyseal extract.

Eppinger, Falta, and Rudinger have made a great many of these experiments, and have added much to the knowledge of the interrelation of the organs of internal secretion. These interrelations they attempt to express in the form of a scheme in which the thyroid, pancreas, and chromaffin system are shown in their relation to one another. In this triangle the thyroid and pancreas are represented as mutually inhibiting one another's activities; so, too, the pancreas and chromaffin system; while the thyroid and chromaffin system promote the activities of one another. On this basis they can explain, without too much forcing, all or nearly all of the phenomena. It must be said, however, that this seems to be merely stating in rather vague phraseology the results, of which we know so little, of the mechanism, and there can be no doubt, in spite of the possible value of this scheme in suggesting further experiments, that a satisfactory explanation can rest only on definite chemical studies.

To me it seems more probable that the chromaffin system is concerned, not with the activity of the pancreas, but with the mobilization of sugar; that the pancreas is similarly concerned, not with inhibiting the activity of the adrenals, but with causing the glycolysis of the free sugar; while the secretion of the thyroid, if in excess, interferes with this glycolytic action of the pancreatic ferment. How far the other organs of internal secretion are concerned in this usually smoothly working mechanism remains to be discovered.

'The literature on any other internal secretion of the pancreas is relatively meager, and most investigators take it for granted that the appearance of fat in the stools in depancreatized animals is merely the effect of the loss of the fat-splitting ferment of the external secretion. The lipemia which sometimes occurs even in human cases of diabetes can not be explained thus, however, and Lombroso has shown that more fat appears in the stools than is taken in with the food, and that it has different characters and a higher melting point than that fed. It must be reexcreted into the intestine. The ligation of the pancreatic duct seems not to produce any such extreme disturbance in the fat metabolism, and on that account the suggestion is made that there may be an internal secretion governing this. Further investigations of this point are necessary.

437 West Fifty-Ninth Street.

Fear.-Fear as an emotion is based on the instinct fundamental to all organisms, that of self-preservation, and so serves an important purpose in safeguarding the individual. In the presence of danger the emotion of fear spurs one on either to flight or to resistance against the threatened danger. When one knows that his life is threatened, his consciously felt enotion of fear is easily explained as a result of that danger. Man's reasoned or rational fears are the fear of death, the fear of pain, and the dread of disesteem. "To the fear of death are ultimately referable all emotions of fear, whether conscious or not; and pain is a motive for dread even when it is not mortal."-W. K. Walker, in Pennsylwania Medical Journal.

\section{PRESENT KNOWLEDGE OF THYROID FUNCTION}

S. P. BEEBE, M.D.

Frofessor of Experimental Therapentics, Cornell Cniversity Medical College

NEW YORK

At the present time we know that the thyroid gland fills a very important function in the animal body. We do not know the precise details as to how this function is fulfilled, and because of our lack of knowledge on this point we may more readily turn the discussion to the consideration of theories than is the case in regard to the other tissues which have been more thoroughly studied and concerning which we have more definite information.

One of these theories is deserving of recognition merely for the purpose of rejection. I reler to the ideas sponsored by Blum, Notkin and others-the so-called neutralization theory. These investigators have stated that the function of the thyroid is to detoxicate certain metabolic products which arise in the animal body, and this action they conceive to take place in the thyroid itself and to be accomplished by the union of iodin with the metabolic product. By such a means the toxic, deleterious effects of these products are prevented, and one of the strongest arguments in support of their theory has been the experiment of Blum who showed that if the secretion from the thyroid gland was artificially combined with iodin, it no longer had characteristic thyroid effects. The more completely these proteins are saturated with iodin the less harmful they are.

Such being the case, it follows that if the extracts of the gland contain little iodin, we should expect very active toxic effects from it since the metabolic toxins have been only partially rendered innocuous. Second, it must follow that if the action takes place only within the thyroid gland, removal of the thyroid must render it impossible for thyroid function to be subserved in such an animal. We know that both of these propositions are incorrect. We know that if thyroid protein is administered to animals and patients in whom the gland is entirely lacking, or pathologically so damaged as to be incapable of function, it causes sluch physiologic changes as to make the animal in most respects normal. The proper functioning of the extract does not require the presence of the gland.

It must be evident, therefore, that the physiologic action of this secretion is exerted on other tissues than the thyroid. We know, likewise, that thyroids containing little iodin show comparatively little of the characteristic thyroid effect, while those containing much iodin are much more active physiologically. There is absolutely no reason whatsoever for supposing that the artificial addition of iodin to the thyroid protein in vitro is in any way comparable to the action which is accomplished by the epithelial cell of the gland. No artificially prepared iodin-containing substance has an effect similar to that of thyroid secretion, or can be used as a substitute for thyroid secretion. Both of these conclusions are well established and they are sufficient to controvert successfully the belief that the thyroid function is entirely accomplished within the gland itself. The function of the gland is to produce a substance which is absorbed into the circulating fluids of the body to act on some of the distant tissues, and it probably is not of benefit to the animal for physiologic purposes except as reserve material while it remains in the gland. Except for the fact that the gland does not have a definite duct, 
there is no reason why it should be classed with the glands of internal secretion.

We know that the physiologically active portion of the gland secretion is a protein substance containing iodin in a specific organic combination. The iodin is pirobally combined with some aromatic group in the molecule. Precisely what its structure is. we do not know. No substance having similar properties has ever been prepared in the laboratory. It does not seem probable that there is only one kind of protein substance which contains iodin. There is a very wide variation in the size of the normal thrroid gland and likewise in the iodin content of the protein taken from glands of individuals who have no apparent thrroid abnormality, as regards either structure or function.

If one attempts to separate the proteins from the the roid gland into various groups, one finds it possible to obtain a number of different fractions, all of which are true proteins and all of which contain iodin, though the iodin content variest widely. I have nover been able to obtain a definite protein or proteose from the throid absolutely free of iodin. This is contrary to the finding of many other investigators. The protein which in $\mathrm{mr}$ experience answers all the phrsiologic requirements is readily prepared from normal thyroid glands by extracting the pulverized tissue with phrsiologic salt solution, filtering through gauze and paper pulp and from this clear filtrate obtaining a precipitate by acidifring with acetic acid and heating to $44 \mathrm{C}$. This protein corresponds to the thyroglobulin described bv Oswald. From the clear filtrate other proteins and proteoses mar b? separated by heating to a higher temperature, ani by the addition of various salts. As previously stated, all these protein fragments contain iodin, lout the protein first separated contains a much larger percentage of iodin than ans of the others. In extracts of beef and pig glands, acetic acid gives an abundant precipitate before heating, but in liuman and sheep glands, the heating is necessary to cause a separation of protein.

It seems probable that the thrroid function is rependent on the presence of jodin in the molecule and most investigators are ayreed that the physiologic activity of the secretion is at least roughly proportional to the iodin content. I believe that we do not ret have convincing evidence that iodin-free throid has characteristic function. Hunt has devised a quantitative method for measuring thyroid activity depending on the protection of mice to aceto-nitrile poisoning. In his hands this method has vielded most remarkable results. In $m$ judgment the iodin ralue is quite as acrurate and much simpler in application.

We have yet no evidence to show that differing qualitative effects are produced hy throid from different types of glands with different iodin values. The normal thrroid contains alveoli filled with the colloid substance which is largely made up of the particular globulin having characteristic thrroid activity. The quantity of this particular protein varies widely in different glands. No structure in the body shows such marked changes in its histologic characteristics as the thyroid.

The facilities for the absorption of this material are apparently not such as to provide for taking up a large quantity in a short space of time, and the question arises as to how large an amount of this material must enter the circulation in a unit of time in order to satisfactorily carry on the thyroid function. As far as we can judge from experimental conditions, the sensitiveness of different animals and different individuals to thrroid shows wicle variations. In some instances I have produced noticeable effect in a human adult by the hypodermic administration of $5 \mathrm{mg}$. of protein prepared as above from normal glands containing between 0.32 and 0.36 mg. of iodin per gram of fresh gland. In other cases, 0.01 gm. has shown decided activity, while 0.06 gm. usually shows quite pronounced effects even in nornual individuals. In several cases of cretinism I have found $0.01 \mathrm{gm}$. of this protein has been effective in completely ameliorating srmptoms. In myxedema, $0.03 \mathrm{gm}$. of these proteins taken each day has kept the symptoms. completely under control. On the other hand, I have had individuals taking $0.5 \mathrm{gm}$. daily for considerable periods without producing any other effect, as far as could be determined, than that of general well-being. 'There is then a very wide variation between the limitof the amount required to maintain health and the anount which an indiridual may take without causing marked phrsiologic disturbance. Furthermore, if so small a quantity of protein as that mentioned is sufficient to satisfy the needs of the average individual for thyroid function, we need not suppose that the venous blood or the lymph coming from a thyroid should contain very much of this secretion. Three-hundredths of a gram of this protein put into the blood which flows through a normal gland in one day (and this has been estimated by Kraus to be fourteen times the total volume of blood in the bodr) would not give an appreciable addition in iodin. It furthermore indicates what a large factor of safety there is in a normal thyroid gland. Such a gland would average about $20 \mathrm{gm}$. in weight from which there might be olstained $3 \mathrm{gm}$. of the protein aloove used or one hundred times the quantity sufficient to fill the demand for this secretion in the case of a myxedematous patient.

Since the isolation of iodothvrin by Baumann it has been believed that the thirroid function might be server. by the use of this small fragment of the protein, but it is my belief that the thyroid function is not in all respects to be filled by this fragment. The physiologic as well as the most effective method of administering thyroid secretion to an animal is to give the same biologic sort of secretion by hypodermic injection. I have in many instances been unable to get the sarne quality of effect or to produce the same change in the metabolism of an animal by administering throid by mouth as could be obtained when giving it directly into the circulation. We do not know on what tissue or set of tissues the thyroid secretion acts. It does not seem to me probable that it is to be compared to the exclusive action of secretin, but rather that most of the tissues in the body are in some way affected by this substance, perhaps in part through the medium of the nervous system. We know that it is connected in some way with the function of oxidation in the body. By the administration of thyroid to a cretin or patient with mrxedema it is possible to increase the absorption of oxygen from 20 to $\% 5$ per cent. There is a corresponding increase in the amount of heat given off from the bodr. The remoral of the thyroid in an animal will cause diminution in the absorption of oxygen which may be again increased by thyroid feeding. Administration of thyroid to a normal animal will cause an increase of from 10 to $\$ 0$ per cent. in the oxygen demand. In comparing myxedema with Graves' disease, we find a very marked contrast in this respect. With the former the absorption of oxygen, the food requirement, the energy exchange is often not more than 40 to 50 per cent. of the normal, while in the latter we see these factors very much increased, occasionally to nearly double the normal. We are again confronted by our 
lack of knowledge when we find that these changes do not always follow thyroid administration.

On the same diet the nitrogen excretion is less when the animal is deprived of the thyroid and markedly increased when thyroid is again given. Such a result is probably merely secondary to the question of oxidation in the different tissues. We do not know why this increased oxidation and nitrogen loss follows administration of thyroid, but Schryver has found that the liver of animals that have been fed on thyroid show during the first twenty-four hours more rapid antolysis than controls. Wells has found that the addition of thyroid to the autolyzing liver has no effect in this respect, but such an experiment is not exactly comparable to Schryver's and does not controvert the accuracy of his results. It seems probable some change has been effected in the liver cell making it more susceptible to autolytic destruction. But a point of great interest is that if the animal is fed for some time on thyroid the rapid autolysis is not seen. A somewhat similar phenomenon is seen in some cases of thyroid feeding to obese persons. A small quantity of thyroid will in the beginning cause a comparatively rapid loss in weight from 10 to 30 pounds, but then a refractory period is reached when a large quantity will cause little or no changes. The character of the nitrogenous metabolism, that is, the distribution of various nitrogenous constituents in the urine, is not markedly different in cases of myxedema and Graves' disease, but I have recently observed instances in which toxic symptoms of somewhat varying type have been associated with high ammonia and higi rest nitrogen fractions in the urine and in which complete symptomatic relief and normal nitrogen divisions in the urine followed the administration of thyroid. It is not possible to say that these individuals were suffering primarily from a lack of thyroid function since there was no other evidence than the facts which $\mathrm{I}$ have stated.

The nitrogen requirement to maintain equilibrium is increased by the addition of thyroid. It has been observed that the protein-sparing power of carbohydrate is less rapidly manifested in the metabolism experiments on animals being fed with thyroid. We may compare such experiments to conditions found in patients suffering from exophthalmic goiter. We find during certain of the acute phases of the disease that the nitrogen requirements are very high indeed. I have seen a patient in the toxic phases lose weight and show a marked nitrogen loss when she was receiving a diet so rich in carbohydrate that she had an alimentary glycosuria; and with a nitrogen intake of $22 \mathrm{gm}$. the nitrogen loss at the same time was $4.5 \mathrm{gm}$. It is not possible to feed such persons a sufficient quantity of any form of diet to entirely prevent nitrogen loss. Such patients may show an elevation of temperature, 1 to.1.5 degrees. They are usually very nervous, although physically weak, and it is evident that we are not dealing "here with physiologic conditions in metabolism in which the usual procedures for preventing nitrogen loss are available, but rather that the excessive quantity of thyroid secretion has so altered the metabolic processes that we have a toxic destruction corresponding to what takes place in some of the infections. Such a phase of the disease does not usually last long.

The thyroid function is in some way concerned with carbohydrate metabolism. Repeated observations have been made showing that the administration of thyroid renders the assimilation or retention of carbohydrate more difficult. Certain facts in regard to this matter have been observed clinically. In severe Graves' disease an alimentary glycosuria is not rare and occasionally a severe and rapidly fatal diabetes develops after this disease when all the other symptoms have been relieved or have abated. In myxedema, on the contrary, the limits of assimilation for carbohydrate are much above those observed normally. In relation to this matter, I will mention an instance of severe fatal diabetes occul'ring in a woman of 53 after recovery from Graves' disease. In this case, the administration of thyroid to the patient caused a marked increase amounting to 90 per cent. in the quantity of sugar excreted as well as marked increase in the excretion of diacetic acid, oxybutyric acid and acetone. The patient at this time had no symptoms of Graves' disease. There was no reason to suppose that the diabetes was in any way concerned with the hyperfunction of the patient's own gland.

One can scarcely discuss this question without referring to the theories which have been advanced by Falta and his co-workers. The supposed interrelations between the thyroid, pancreas and adrenal, which they have worked out, are suggestive and possibly point to a future explanation of some of these matters. The experimental results which they have used thus far to substantiate their theory are only suggestive, and in my judgment they have proved nothing more than that further investigation along those lines is necessary.

The reaction on the pupil of the enucleated frog's eye has been used to show an antagonistic action between the adrenal and the thyroid. Such a reaction indicates that we may get some antagonistic action between these two glands, but although we must suspect that the thyroid is closely related with other glands in the body, and we may say that we know that such interrelations probably exist, the majority of these theories regarding these interrelations are based on pathologic and clinical observations and not on accurate experimentation.

Attempts have been made to demonstrate that the thyroid gland serves a particularly valuable function in combating infections in the body. The expressed juices of the thyroid have been allowed to act directly on bacteria with apparent bactericidal effect, but not in any respect more than was obtained from extracts of the liver and kidney. The quantity of the alexin in the blood has been found to be increased in those animals to which thyroid has been given, and it is a commonly observed fact that cretinous and myxedematous patients do not bear infections well, while on the other hand certain observers believe that every infection stimulates the thyroid to additional activity. It is certainly open to question whether a specific effect in infections is to be ascribed to the thyroid. It rather appears that the effect is a general one and it seems improbable that the thyroid function is one of the specific means by which the body protects itself from infectious diseases.

From the evidence which is now obtainable I think we must conclude that the thyroid gland furnishes a hormone which may be present in the blood within wide limits in the condition which we call health, and which stimulates a variety of tissues to a physiologic, and at times a pathologic, degree of activity.

\footnotetext{
Occupation in Treatment of Neurasthenia.-Healthy occupation of body and mind, says D. Ferrier in the Practitioner, never does any harm to the most pronounced neurasthenic, but the reverse. If work at first is hard, it becomes easier by degrees, and patients who find the régime a hard one should be told that it is better to be ill at work than ill in idleness. The misfortune is that so many neurasthenics have neither the determination nor the courage to submit to the necessary training of their morals, and thus go to swell the crowd of able-bodied valetudinarians."
} 